\title{
Lower Pole Dermoglandular Flap Autoaugmentation versus Mastopexy Augmentation with Subpectoral Implants: Outcomes after Reshaping of Ptotic Breasts
}

\author{
ISSAM MOHAMED ELMEKKAWI, M.Sc.*; AHMED MOHAMED BAHAA ELDIN, M.D.**; \\ MOHAMED RADWAN ELHADIDY, M.D.** and AHMED M. ZEINA, M.D.** \\ Specialist of Plastic Surgery, Ministry of Health* and Department of Plastic \& Reconstructive Surgery**, Faculty of Medicine, \\ Mansoura University, Egypt
}

\begin{abstract}
Background: Single stage augmentation mastopexy is a challenging procedure for both volume expansion and skin envelope reduction. Also, the patient experience is an important issue after mastopexy as it affects the patient physical functioning, psychosocial wellbeing, and the aesthetic result.
\end{abstract}

Aim: To assess the outcomes of reshaping of a ptotic breast and its impact on the quality of life.

Patients and Methods: This prospective comparative study was conducted over a 2-year period in 32 female patients with different degrees of breast ptosis. Patients were divided into two groups according to their desire to increase breast volume either using or not using an implant. Standard breast measurements as well as early and late complications were recorded, and patient satisfaction was assessed using the BREAST-Q.

Results: Postoperatively, both the groups showed significant improvements in ptosis and in the BREAST-Q scores compared to pre-operative scores in all domains ( $p \leq 0.001)$. However, regarding post-operative satisfaction with breast volume, psychosocial wellbeing, and outcomes, the autoaugmentation group showed a significantly higher BREAST-Q score compared with the implant augmentation group $(p \leq 0.05)$.

Conclusion: The BREAST-Q provides significant clinical information and evaluates the influence of the surgical procedure on the patient's regular life activities. Mastopexy autoaugmentation using the lower pole dermoglandular flap is a reliable technique for enhancing the projection of the breast, improving the upper pole shape, and creating an adequate breast volume with a low complication rate and high patient satisfaction.

Key Words: Augmentation - Autoaugmentation - Breast Mastopexy augmentation - Implant - Ptosis Quality of life - Satisfaction.

\section{INTRODUCTION}

The breast has been described consistently as equally contoured, non-ptotic, and youthful [1]. Many factors such as aging, rapid weight loss and pregnancy reduce breast tissue elasticity and cause ptosis. Breast ptosis is characterized by the loss of breast volume, loose skin, and breast parenchyma involution. It is associated with volume loss noticeable mainly in the upper pole and the expansion of the lower pole of the breast, resulting in a wide and flat breast [2].

Ptosis is classified according to the position of the nipple areola complex (NAC) in relation to the inframammary fold (IMF). In grade I (mild) ptosis, the NAC is located at the level of the IMF. In grade II (moderate) ptosis, the NAC lies below the level of the IMF but above the most dependent part of breast parenchyma. In grade III (severe) ptosis, the NAC is below the IMF at the most dependent part of the parenchyma along the inferior breast contour [3].

The goal of mastopexy is to reshape the breast by forming a breast cone on the normal anatomical base using misplaced and deformed breast tissue [4]. Performing mastopexy in patients with small sized and medium sized ptotic breasts presents one of the greatest challenges to plastic surgeons because mastopexy has opposing effects on breast skin and parenchyma in patients with small sized and medium sized ptotic breasts. The goals of these procedures include obtaining a more youthful appearance, improved projection, and reduced ptosis of the breast [5].

In breast reduction surgery, breast skin and tissue are removed. However, in mastopexy, breast skin is removed, but breast parenchyma is rearranged [6]. This is the main difference between mastopexy and breast reduction. Many surgical procedures such as periareolar mastopexy, vertical mastopexy, and Wise pattern procedures have been designated, but the most recent types of mastopexy 
include the manipulation of parenchyma to improve the longevity of breast ptosis correction [7]. Single stage augmentation mastopexy has been shown to be a reliable option for carefully selected patients who wish to correct both the shape and volume of the breast [8].

Augmentation mastopexy with breast implants produces a fuller upper pole of the breast and a more projected breast. Augmentation mastopexy with autoaugmentation is an option for patients who do not desire an implant, and the result is closer without an implant [9]. Numerous techniques, such as redistribution of superiorly or inferiorly based glandular flap, suspension to the deep fascia or the periosteum, the use of muscle or fascial slings, have been developed to attain upper pole fullness and better stability of the results. Previous studies described glandular reshaping using the lateral chest wall perforator flaps, upper abdominal perforator flaps, or synthetic mesh [10].

Aesthetic outcomes research in plastic surgery now not only examines morbidity and mortality but also evaluates patient experiences regarding results and improvement in quality of life. The BREAST-Q is patient reported outcome instrument designed to assess outcomes among women undergoing breast surgery. The framework includes two overarching domains: Health related quality of life and patient satisfaction. First domain (health related quality of life) includes three subdomains: Psychosocial, physical, and sexual wellbeing. Second domain (patient satisfaction) includes three subdomains: Satisfaction with breasts, satisfaction with overall outcome and satisfaction with care. Each module has both pre-operative and postoperative versions [11].

Regarding mastopexy combined with autoaugmentation, the literature is relatively heterogeneous due to different surgical procedures and outcome definitions [12]. In this study, breast ptosis was corrected using mastopexy autoaugmentation using the superomedial NAC pedicle and lower pole dermoglandular flap or implant to improve upper pole fullness and enhance breast projection.

\section{PATIENTS AND METHODS}

This was a prospective comparative study conducted over a 2-year period, starting from December 2018 at the Department of Plastic \& Reconstructive Surgery, Mansoura University. This study included 32 female patients with different degrees of breast ptosis who underwent mastopexy; they were aged between 24 and 48 years. Patients were divided into two groups according to their desire to increase breast volume either using or not using an implant. In the group A, patients underwent mastopexy autoaugmentation; in the group B, patients underwent single stage mastopexy augmentation with breast implants. The study was approved by the Institutional Review Board (IRB) of the Mansoura Faculty of Medicine (R.18.07.61). Informed consent was obtained from all patients. All patients were assessed based on their detailed medical history; they also underwent thorough physical examination and radiological investigations. All patients were operated by senior authors, precise breast measurements were recorded; preoperative and postoperative pictures of the breast were taken.

In group A, the breasts were marked with the patient in the standing position using a Wise pattern and superomedial based pedicle. The midlines from the sternal notch to the xiphoid process, IMF, and breast meridians were drawn (Fig. 1). The new nipple site was marked on the breast meridian at the level of the IMF, usually 20 to 22 from the suprasternal notch. The keyhole was marked around the new nipple site. The lateral and medial vertical limbs were marked by advancing the breast mound medially and laterally, the length is 5 to $7 \mathrm{~cm}$ from the bottom of the keyhole. The lower ends of the vertical limbs were connected to the line drawn in the IMF medially and laterally. This horizontal line was drawn as short as possible, not exceeding the lateral sternal border medially and anterior axillary line laterally. The lower pole dermoglandular flap, which was used for autoaugmentation, was marked with a base of approximately $10 \mathrm{~cm}$ centered on the breast meridian; the height was drawn $1 \mathrm{~cm}$ below the lower edge of the areola, and it is usually $10 \mathrm{~cm}$.

The areola was marked with a $42 \mathrm{~mm}$ areola marker. The keyhole, NAC pedicle, and lower pole dermoglandular flap were deepithelialized (Fig. 1). The superomedial NAC pedicle was elevated on a full thickness pedicle, which could not be thinned less than $3 \mathrm{~cm}$ to preserve its blood and nerve supply. The width of the pedicle was partially extended to the keyhole and most of the medial vertical limb. Dissection and isolation of the lower pole flap using monopolar cautery without undermining of the flap. Dissection and creation of subglandular pocket in superomedial direction up to the level of upper breast border then the lower pole autoaugmentation flap is transposed superomedially and fixed to the pectoral fascia using interrupted absorbable suture (Fig. 2). 
The NAC was rotated and fixed on the midline at the $12 \mathrm{o}$ 'clock position. If the pedicle rotation was not adequate, a back cut was considered in the dermis of the lower portion to facilitate rotation and avoid tethering. The vertical limbs medial and lateral pillars were sutured together. Tailor tacking was performed before the final closure. The periareolar area, vertical and horizontal limb closure with dermal and subcuticular sutures (Figs. 3,5,6).

In group $\mathrm{B}$, the initial marking was performed as before with the main land marking IMF, the upper breast border, and the lateral and medial boundaries of the breasts. The new nipple site was initially marked on the breast meridian at the level of the IMF or parallel to the mid arm. These markings were mainly used as guidelines for establishing symmetry, and the final position of the nipples was centralized over the breast mound after implant insertion. Mastopexy incisions were made according to the degree of ptosis either periareolar for patients with minimal ptosis, vertical for patients with moderate ptosis or Wise pattern for patients with severe ptosis. Implants were inserted through periareolar incision in patients with mild and moderate ptosis and through inframammary incision in patients with severe ptosis. A precise subpectoral pocket was created, and the implant (Silitex ${ }^{\circledR}$ round high profile, $300 \mathrm{cc}$ to $375 \mathrm{cc}$ ) was inserted after meticulous hemostasis and pocket irrigation with antibiotic solution. The pocket was closed in layers, and the patient was placed in the setting position (Fig. 4). Mastopexy was performed using tailor-tacking technique to evaluate and determine the amount of skin to be deepithelialized (Fig. 7). Skin redundancy inferiorly was converted into the $\mathrm{J}, \mathrm{L}$, or T closure pattern.

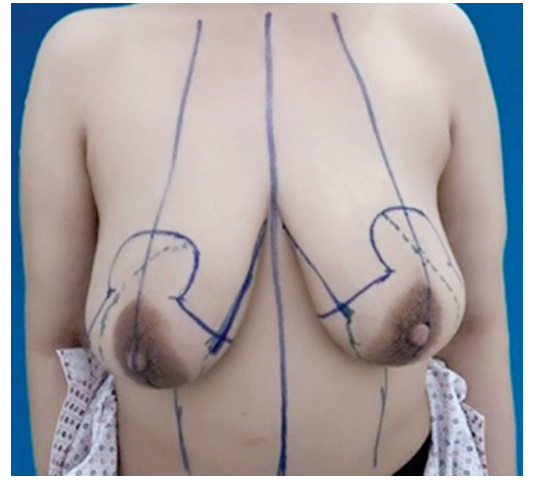

(A)

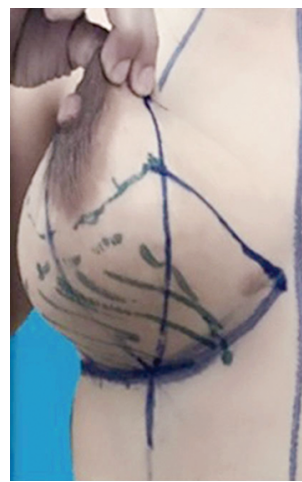

(B)

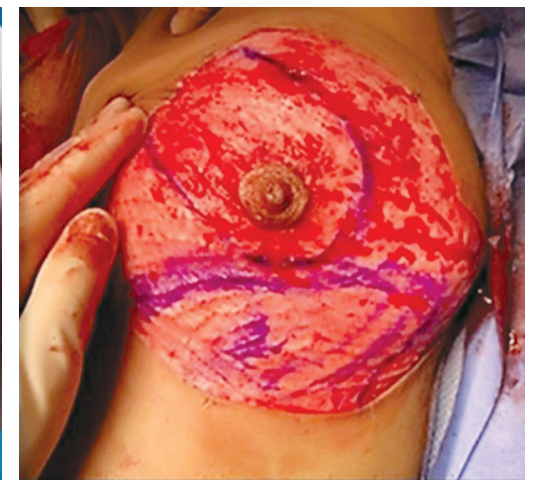

(C)

Fig. (1): (A): Pre-operative marking with superior medial pedicle. (B): Marking of lower pole autoaugmentation flap. (C): Deepithelization of the keyhole, NAC pedicle, and the lower poledermoglandular flap.

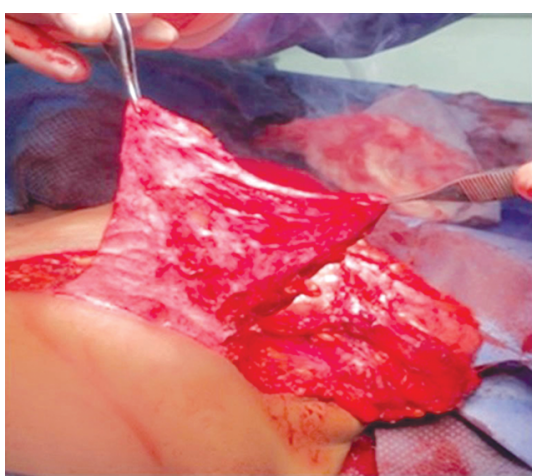

(A)

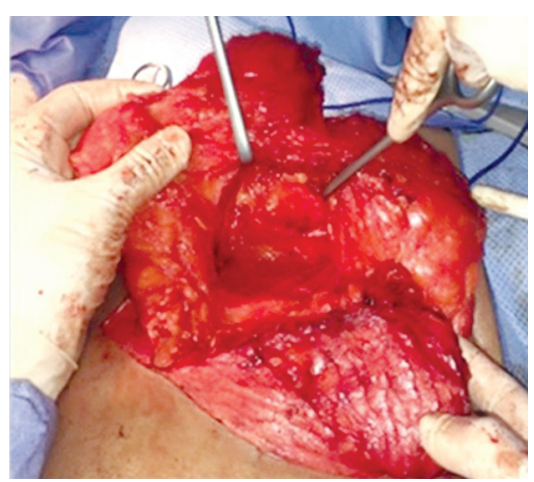

(B)

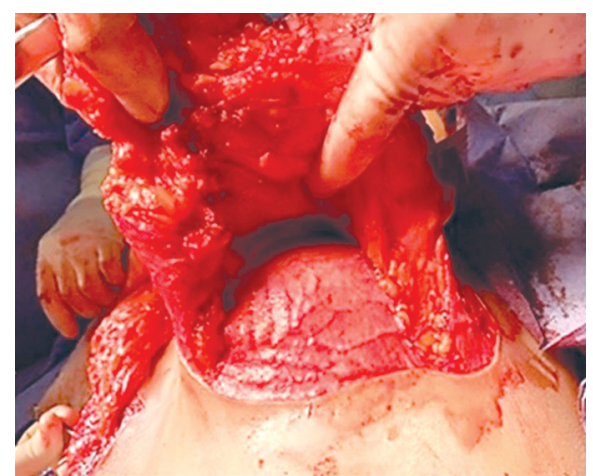

(C)

Fig. (2): (A): Shows isolation of the lower pole autoaugmentation flap. (B): Shows dissection and creation of subglandular pocket in superomedial direction up to the level of upper breast border. (C): Shows the lower pole autoaugmentation flap is transposed superomedially and fixed to the pectoral fascia. 


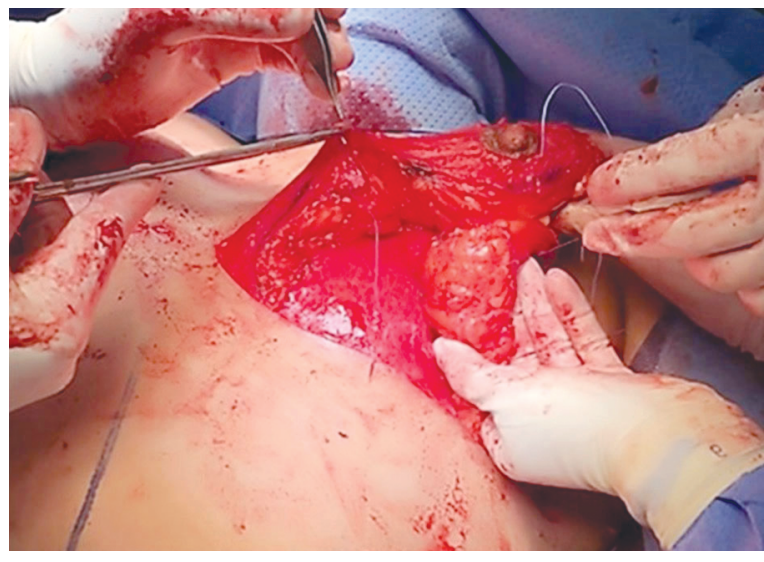

(A)

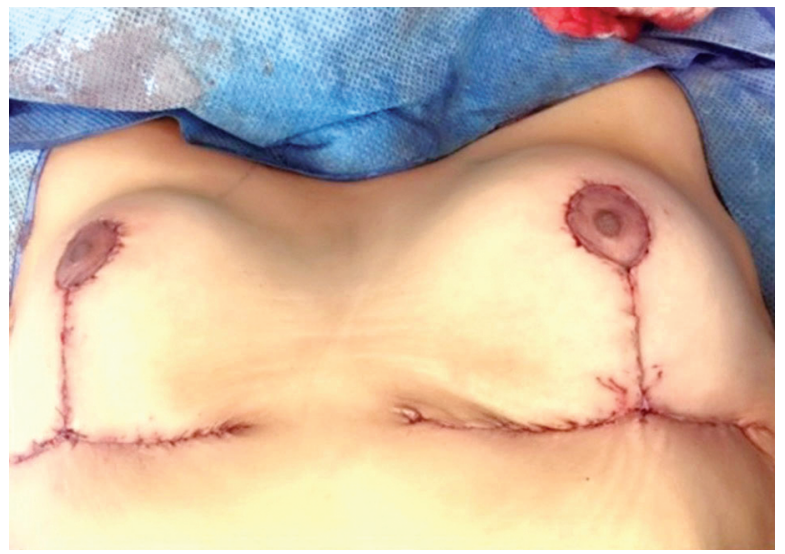

(B)

Fig. (3): (A): Shows the medial and lateral pillars are sutured together. (B): Shows final closure.

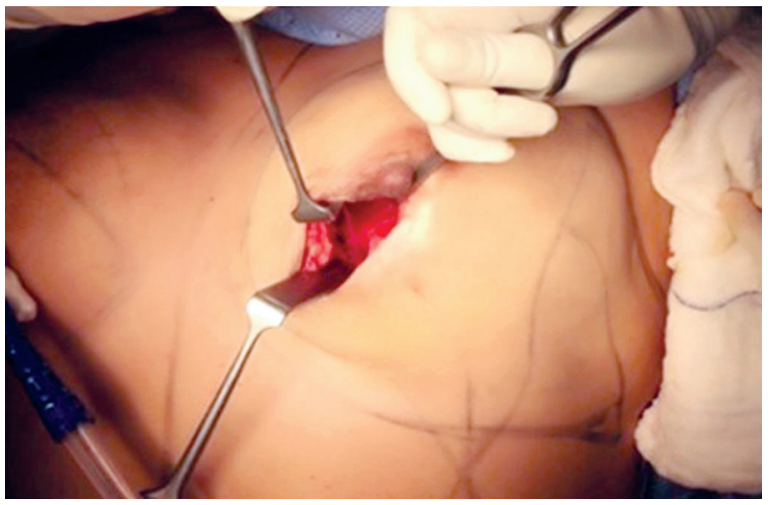

(A)

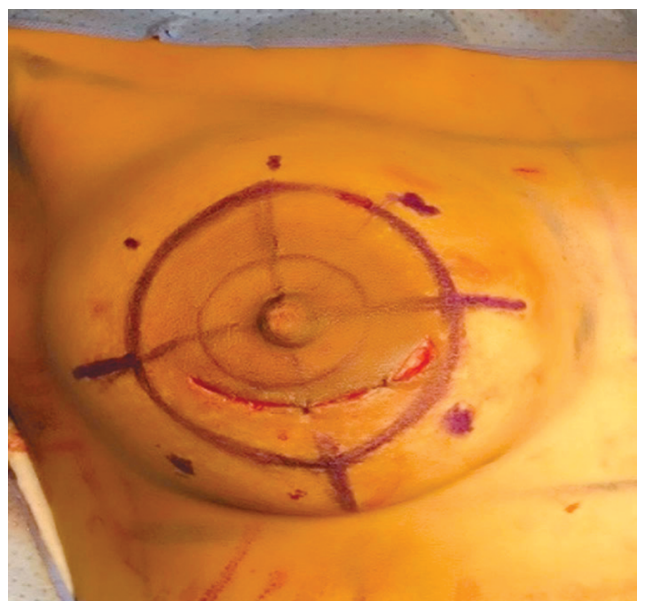

(C)

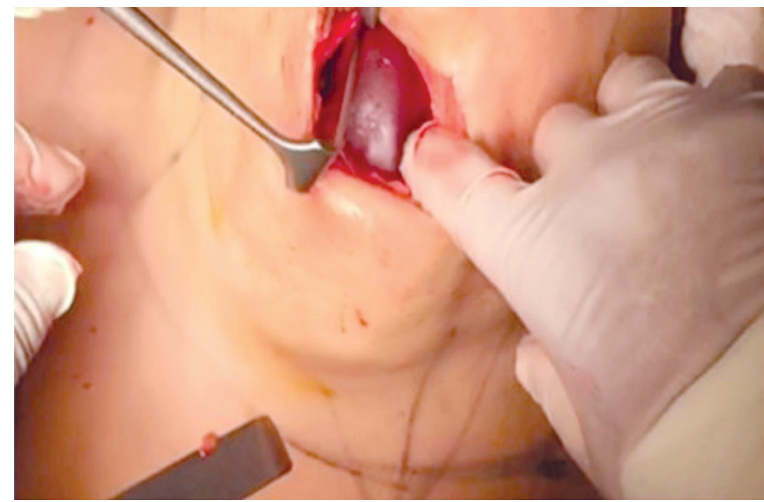

(B)

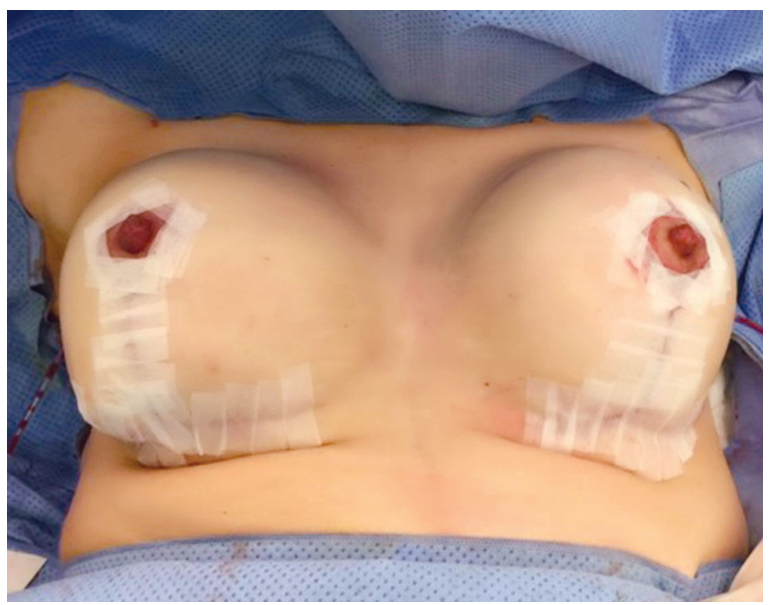

(D)

Fig. (4): (A,B): Insertion of breast implant. (C): Shows periareolar mastopexy with interlocking purse-string suture. (D): Tailortacking and the skin redundancy inferiorly is converted into $\mathrm{T}$ closure pattern. 

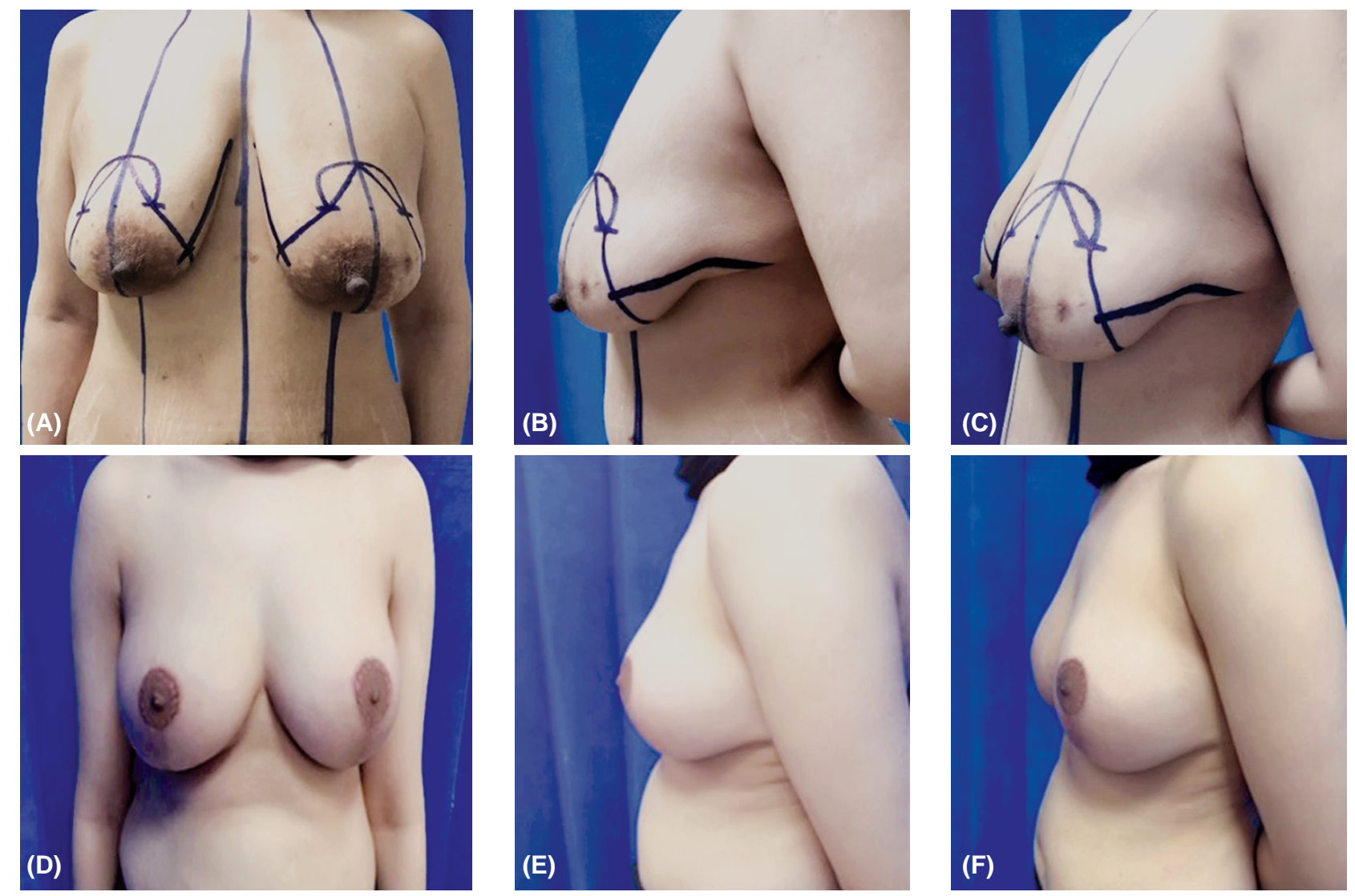

Fig. (5): Pre-operative (A,B,C) and postoperative (D,E,F) follow-up case of mastopexy autoaugmentation.
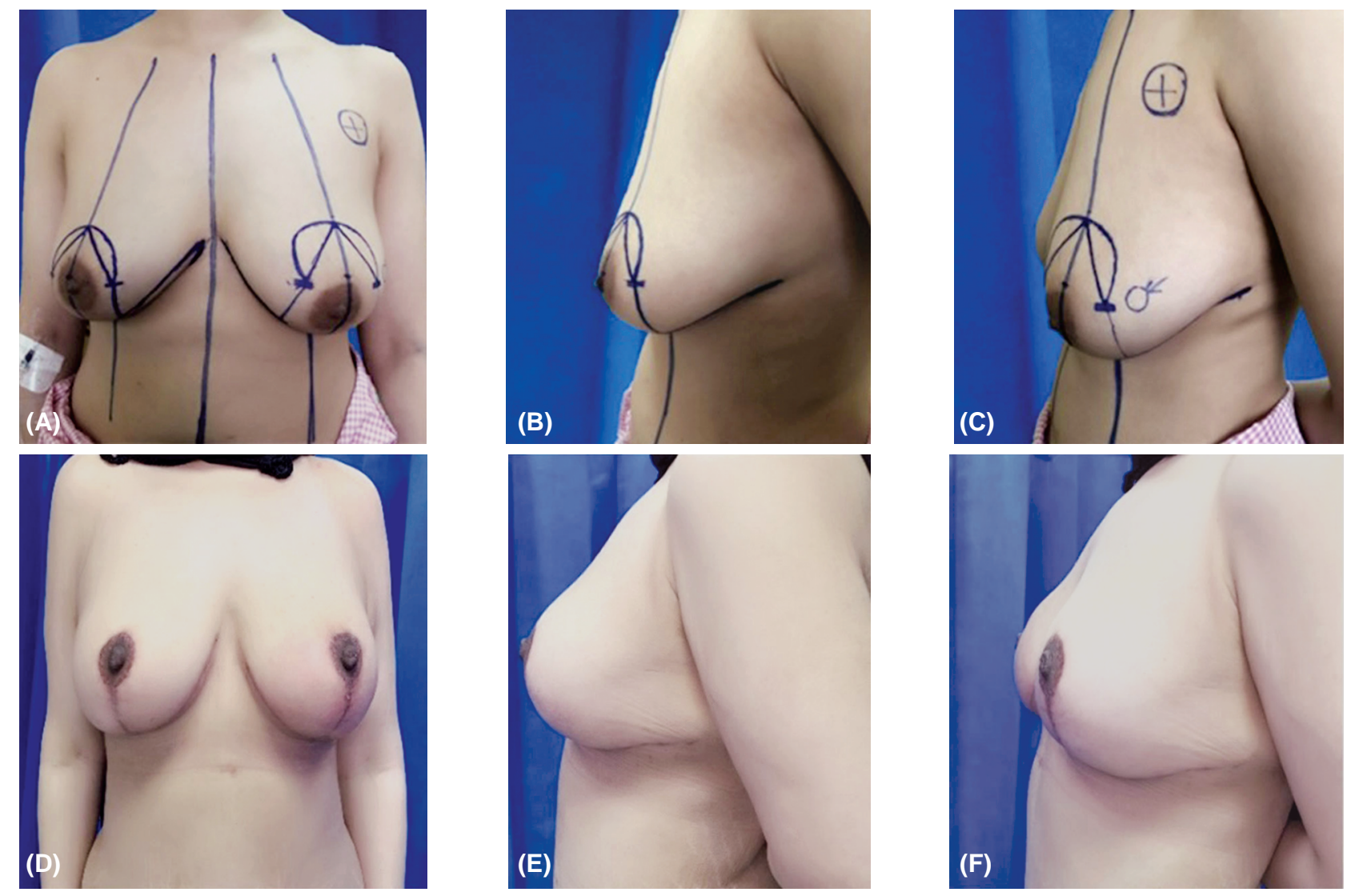

Fig. (6): Pre-operative (A,B,C) and postoperative (D,E,F) follow-up case of mastopexy autoaugmentation. 
(A)

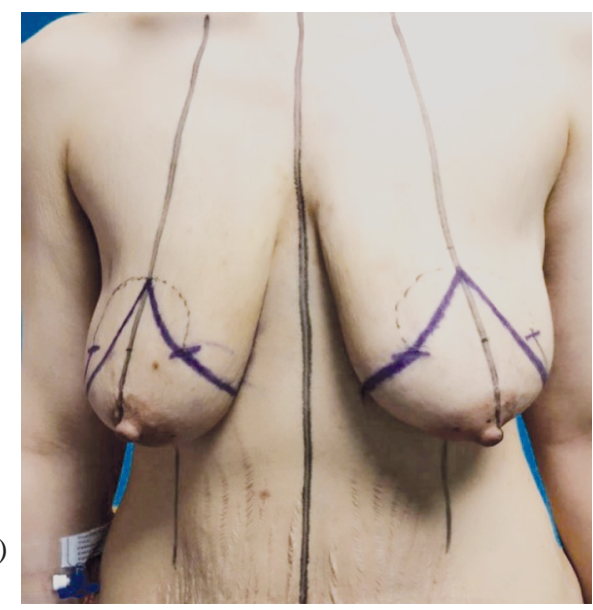

(C)

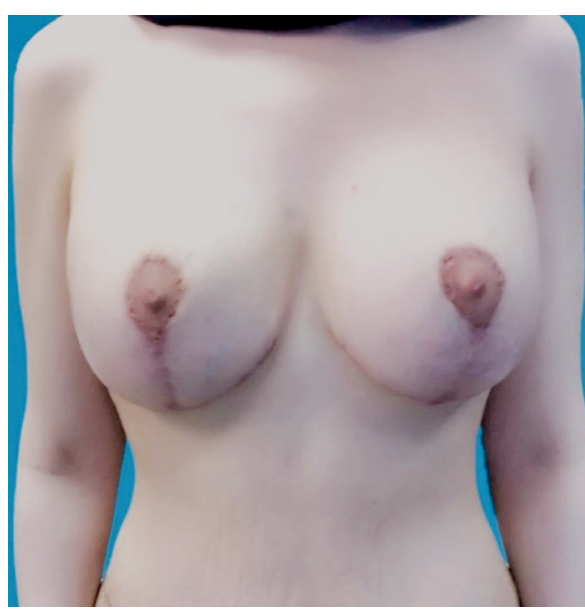

(B)

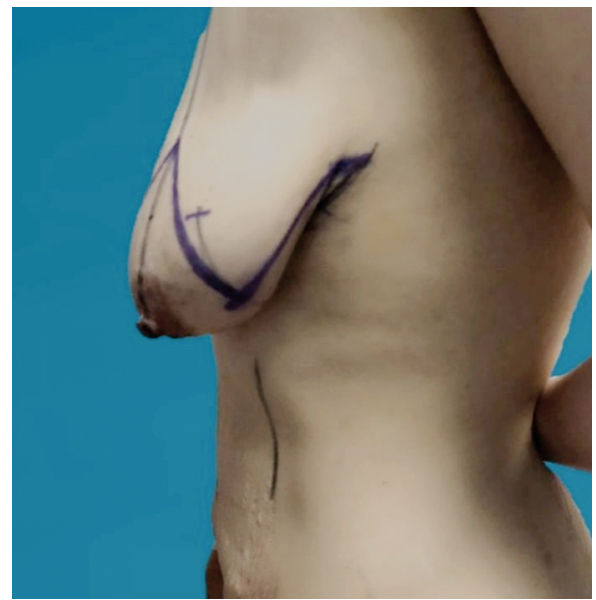

(D)

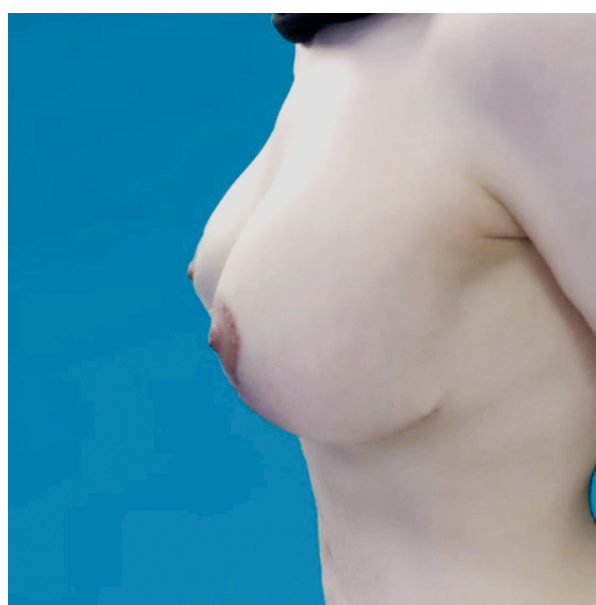

Fig. (7): Pre-operative (A, B) and post-operative (C, D) follow-up case of implant mastopexy augmentation.

Patients were evaluated immediately and one year after the surgery to determine the primary outcome, which was defined as standard breast measurements such as the distance between the sternal notch and the nipple (SN-N), the nipple and the IMF (N-IMF) during stretching, and the secondary outcome, which was defined as early and late complications as well as patient satisfaction. Patient satisfaction was assessed preoperatively and one year postoperatively using the BREAST-Q(Memorial Sloan-Kettering Cancer Center and the University of British Columbia, all rights reserved).

\section{Statistical analysis:}

Data were analyzed using the Statistical Package of Social Science (SPSS) program for Windows (Standard version 24). The calculated sample size of the study was 12 participants for each group at $5 \%$ level of significance and $80 \%$ power, using the following formula: $\mathrm{N}=(\mathrm{Z} 1-\alpha / 2+\mathrm{Z} 1-\beta)^{2} \sigma 1^{*} \sigma^{2}$ $/ \delta^{2}, \mathrm{Z} 1-\alpha / 2=1.96, \mathrm{Z} 1-\beta=0.842, \sigma=\mathrm{SD}$ [12]. The normality of data was first tested with one-sample Kolmogorov-Smirnov test. Continuous variables were presented as mean \pm SD (standard deviation) for parametric data. Association between categorical variables was tested using Chi-square test while Fischer exact test were used when expected cell count less than 5. The two groups were compared with Student $t$-test while paired groups were compared by paired $t$-test. The results were considered significant when the probability of value is less than $5 \%(p<0.05)$.

\section{RESULTS}

The group A included 19 patients with a mean age of $34.84 \pm 8.14$ years who underwent mastopexy autoaugmentation using the lower pole dermoglandular flap suspended superiorly to the pectoral fascia to improve the upper breast fullness and enhance the projection. The group B included 13 patients with a mean age of $31.69 \pm 4.58$ years who underwent single stage mastopexy augmentation with a subpectoral breast implant. No statistically significant difference in demographic data was observed between the two groups as shown in Table (1). 
Table (1): Demographic data and patients' characteristics among autoaugmentation (group A) and mastopexy augmentation (group B).

\begin{tabular}{|c|c|c|c|c|}
\hline Variables & $\begin{array}{c}\text { Group A } \\
(\mathrm{n}=19)\end{array}$ & $\begin{array}{c}\text { Group B } \\
(\mathrm{n}=13)\end{array}$ & $\begin{array}{c}\text { Test of } \\
\text { significance }\end{array}$ & $p$-value \\
\hline \multicolumn{5}{|l|}{ Age (years): } \\
\hline Mean \pm SD & $34.84 \pm 8.14$ & $31.69 \pm 4.58$ & $t=1.260$ & 0.217 \\
\hline \multicolumn{5}{|l|}{ Marital status: } \\
\hline Married & $13(68.4 \%)$ & $5(38.5 \%)$ & $\chi^{2}=2.81$ & 0.093 \\
\hline Single & $6(31.6 \%)$ & $8(61.5 \%)$ & & \\
\hline No medical history & $15(78.9 \%)$ & $9(69.2 \%)$ & $\mathrm{MC}$ & 0.702 \\
\hline Gastric sleeve & $3(15.8 \%)$ & $2(15.4 \%)$ & & \\
\hline Massive weight loss by diet & $0(0 \%)$ & $1(7.7 \%)$ & & \\
\hline Diabetic mellitus & $0(0 \%)$ & $1(7.7 \%)$ & & \\
\hline SLE (systemic lupus) & $1(5.3 \%)$ & $0(0 \%)$ & & \\
\hline Body mass index & $27.89 \pm 2.20$ & $27.38 \pm 1.98$ & $t=0.668$ & 0.509 \\
\hline \multicolumn{5}{|l|}{ Skin quality: } \\
\hline Good & $6(31.6 \%)$ & $6(46.2 \%)$ & $\mathrm{MC}$ & $0.007 *$ \\
\hline Striae $+($ mild $)$ & $1(5.3 \%)$ & $3(23.1 \%)$ & & \\
\hline Striae $++($ moderate $)$ & $10(52.6 \%)$ & $0(0 \%)$ & & \\
\hline Striae $+++($ sever $)$ & $2(10.5 \%)$ & $4(30.8 \%)$ & & \\
\hline \multicolumn{5}{|l|}{ Asymmetry: } \\
\hline No & $8(42.1 \%)$ & $10(76.9 \%)$ & $\mathrm{MC}$ & 0.113 \\
\hline Rt more ptotic & $5(26.3 \%)$ & $3(23.1 \%)$ & & \\
\hline Lt more ptotic & $5(26.3 \%)$ & $0(0 \%)$ & & \\
\hline IMF & $1(5.3 \%)$ & $0(0 \%)$ & & \\
\hline \multicolumn{5}{|l|}{ Ptosis: } \\
\hline Grade II & $3(15.8 \%)$ & $7(53.8 \%)$ & $\chi^{2}=5.20$ & $0.023^{*}$ \\
\hline Grade III & $16(84.2 \%)$ & $6(46.2 \%)$ & & \\
\hline
\end{tabular}

$t$ : Student $t$-test, $\chi^{2}$ : Chi square test, MC: Monte carlo test, *Significant $p \leq 0.05$, Rt: Right, Lt: Left, IMF: Inframammary fold.

According to the Regnault classification of breast ptosis, there were three (15.8\%) and seven $(53.8 \%)$ patients with grade II ptosis in the group A and group B, respectively. There were $16(84.2 \%)$ and $6(46.2 \%)$ patients with grade III ptosis in the group A and group B, respectively. In the group A, breast cup size was C $(94.7 \%)$ and D (5.3\%). In the group B, breast cup size was B $(46.2 \%)$ and C $(53.8 \%)$. A statistically significant difference was observed between the groups in terms of skin quality. The number of patients with good skin quality and mild stria was higher in the group B than that in the group A.

There was a significant improvement in ptosis in both the groups $(p \leq 0.001)$ (Table 2$)$. In the group A, the pre-operative and post-operative values of $\mathrm{SN}-\mathrm{N}$ ranged between $23 \mathrm{~cm}$ and $33 \mathrm{~cm}(28.23 \pm$ $3.13 \mathrm{~cm})$ and between $20 \mathrm{~cm}$ and $21 \mathrm{~cm}(20.31 \pm$ $0.47)$, respectively. The pre-operative value of $\mathrm{N}$ IMF ranged between $10 \mathrm{~cm}$ and $15 \mathrm{~cm}(12.89 \pm$
$1.51 \mathrm{~cm})$, and the value of N-IMF was between $6.5 \mathrm{~cm}$ and $10.5 \mathrm{~cm}(7.81 \pm 1.00 \mathrm{~cm})$ one year postoperatively. In the group B, the pre-operative and post-operative values of $\mathrm{SN}-\mathrm{N}$ ranged between $23 \mathrm{~cm}$ and $36 \mathrm{~cm}(26.84 \pm 3.85 \mathrm{~cm})$ and between $20 \mathrm{~cm}$ and $24 \mathrm{~cm}(21.07 \pm 1.45 \mathrm{~cm})$. The pre-operative value of N-IMF ranged between $9 \mathrm{~cm}$ and $14 \mathrm{~cm}(11.26$ $\pm 2.04 \mathrm{~cm}$ ), and the value of N-IMF was between 6.5 and $11 \mathrm{~cm}(8.03 \pm 1.28 \mathrm{~cm})$ one year postoperatively.

During the early post-operative period, wound dehiscence occurred in one case $(5.3 \%)$ in the group A (at the convergence of Wise pattern incision) and in two cases (15.4\%) in the group B (one at the convergence of Wise pattern incision and the other one in the periareolar incision) (Table 3).

Two cases (10.5\%) in the group A showed mild bottoming out (N-IMF was $10 \mathrm{~cm}$ and $10.5 \mathrm{~cm}$ ). On the other hand, four patients $(30.7 \%)$ in the group 
B showed late post-operative complications. Among them, two patients developed recurrent ptosis (SN$\mathrm{N}$ was $24 \mathrm{~cm}$ in both cases) and a wide scar. Additional two patients showed $(1 \mathrm{~cm}$ difference in $\mathrm{SN}-$ $\mathrm{N}$ between both side) and waterfall deformity, which was mild in one case and was reported by the patient in other case (Table 3). The complication rate was higher in the group $B$ than that in the group A although the difference was not statistically significant $(p=0.194)$.

In both the groups, post-operative BREAST-Q scores showed significant improvement in all domains than preoperative BREAST-Q scores $(p \leq 0.001)$ (Tables 4,5). No statistically significant difference was observed between the groups in terms of satisfaction with the NAC, satisfaction

Table (2): Comparison between autoaugmentation (group A) and mastopexy augmentation (group B) regarding breast measurements.

\begin{tabular}{lllcc}
\hline & $\begin{array}{c}\text { Group A } \\
(\mathrm{n}=19)\end{array}$ & \multicolumn{1}{c}{$\begin{array}{c}\text { Group B } \\
(\mathrm{n}=13)\end{array}$} & $\begin{array}{c}\text { Test of } \\
\text { significance }\end{array}$ & $\begin{array}{c}p \text { - } \\
\text { value }\end{array}$ \\
\hline SN-N (Pre) & $28.23 \pm 3.13$ & $26.84 \pm 3.85$ & 1.123 & 0.271 \\
SN-N (post) & $20.31 \pm 0.47$ & $21.07 \pm 1.45$ & 2.585 & $0.015^{*}$ \\
Paired $t$-test & $t=11.13$ & $t=6.95$ & - & - \\
$(p)$ & $p \leq 0.001^{*}$ & $p \leq 0.001^{*}$ & & \\
N-IMF (Pre) & $12.89 \pm 1.51$ & $11.26 \pm 2.04$ & 2.131 & $0.041^{*}$ \\
N-IMF (post) & $7.81 \pm 1.00$ & $8.03 \pm 1.28$ & 0.551 & 0.586 \\
Paired $t$-test & $t=16.83$ & $t=7.72$ & - & - \\
$(p)$ & $p \leq 0.001 *$ & $p \leq 0.001^{*}$ & & \\
\hline
\end{tabular}

SN-N : Sternal notch to nipple distance.

N-IMF: Nipple to Inframammary fold distance.

*Significant $p \leq 0.05$.

Table (4): Breast Q pre-operative and after one year in group A.

\begin{tabular}{|c|c|c|c|c|}
\hline \multirow{2}{*}{ Breast Q } & \multicolumn{2}{|c|}{ Group A $(n=19)$} & \multirow{2}{*}{$\begin{array}{c}\text { Test of } \\
\text { significance }\end{array}$} & \multirow{2}{*}{$\begin{array}{c}p- \\
\text { value }\end{array}$} \\
\hline & Pre-operative & One year & & \\
\hline $\begin{array}{l}\text { Satisfaction } \\
\text { with breasts }\end{array}$ & s $25.05 \pm 9.79$ & $82.68 \pm 5.51$ & 22.33 & $\leq 0.001 *$ \\
\hline $\begin{array}{l}\text { Psychosocial } \\
\text { well-Being }\end{array}$ & $22.36 \pm 8.44$ & $87.05 \pm 7.06$ & 20.85 & $\leq 0.001 *$ \\
\hline $\begin{array}{l}\text { Physical } \\
\text { well-being }\end{array}$ & $27.63 \pm 12.26$ & $82.73 \pm 7.27$ & 16.76 & $\leq 0.001 *$ \\
\hline $\begin{array}{l}\text { Sexual } \\
\text { well-being }\end{array}$ & $26.00 \pm 11.47$ & $87.05 \pm 6.44$ & 19.78 & $\leq 0.001 *$ \\
\hline
\end{tabular}

*Significant $p \leq 0.05$. with information, satisfaction with the surgeon, satisfaction with the medical team, and satisfaction with hospital staff.

The BREAST-Q scores regarding post-operative satisfaction with the breast, psychosocial wellbeing, and satisfaction with outcome were significantly higher in the group A compared with those in the group B $(p \leq 0.05)$ (Table 6$)$. The BREAST$\mathrm{Q}$ score regarding postoperative satisfaction with the breast was $82.68 \pm 5.51$ in the group A compared with $77.84 \pm 6.13$ in the group B. The BREAST-Q score regarding psychosocial well-being was 87.05 \pm 7.06 in the group A compared with $80.00 \pm 8.76$ in the group B. The BREAST-Q score regarding satisfaction with outcome was $86.63 \pm 6.99$ in the group A compared with $79.92 \pm 8.64$ in the group B.

Table (3): Comparison between both groups regarding Postoperative complications.

\begin{tabular}{lccc}
\hline $\begin{array}{l}\text { Early post-operative } \\
\text { complications }\end{array}$ & $\begin{array}{c}\text { Group A } \\
(\mathrm{n}=19)\end{array}$ & $\begin{array}{c}\text { Group B } \\
(\mathrm{n}=13)\end{array}$ & $\begin{array}{c}p- \\
\text { value }\end{array}$ \\
\hline $\begin{array}{l}\text { No complications } \\
\text { Wound dehiscence }\end{array}$ & $\begin{array}{l}18(94.7 \%) \\
1(5.3 \%)\end{array}$ & $\begin{array}{l}11(84.6 \%) \\
2(15.4 \%)\end{array}$ & 0.552 \\
$\begin{array}{l}\text { Late post-operative } \\
\text { complications }\end{array}$ & Group A & Group B & $p$-value \\
\hline Total & $2(10.5 \%)$ & $4(30.7 \%) \#$ & 0.194 \\
\hline Bottoming out & $2(10.5 \%)$ & - & \\
Wider scar & - & $2(15.3 \%)$ & \\
$\begin{array}{l}\text { Asymmetry } \\
\text { Recurrent ptosis }\end{array}$ & - & $2(15.3 \%)$ & \\
Waterfall deformity & - & $2(15.3 \%)$ & \\
\hline
\end{tabular}

\# The case can have more than one complication at the same time.

Table (5): Breast Q pre-operative and after one year in group

\begin{tabular}{|c|c|c|c|c|}
\hline \multirow{2}{*}{ Breast Q } & \multicolumn{2}{|c|}{ Group B } & \multirow{2}{*}{$\begin{array}{c}\text { Test of } \\
\text { significance }\end{array}$} & \multirow{2}{*}{$\begin{array}{c}p- \\
\text { value }\end{array}$} \\
\hline & Pre-operative & One year & & \\
\hline $\begin{array}{l}\text { Satisfaction } \\
\text { with breasts }\end{array}$ & $27.76 \pm 6.66$ & $77.84 \pm 6.13$ & 23.83 & $\leq 0.001 *$ \\
\hline $\begin{array}{c}\text { Psychosocial } \\
\text { well-Being }\end{array}$ & $27.46 \pm 8.95$ & $80.00 \pm 8.76$ & 14.52 & $\leq 0.001 *$ \\
\hline $\begin{array}{l}\text { Physical } \\
\text { well-being }\end{array}$ & $24.92 \pm 10.79$ & $81.53 \pm 10.13$ & 13.65 & $\leq 0.001 *$ \\
\hline $\begin{array}{l}\text { Sexual } \\
\text { well-being }\end{array}$ & $31.07 \pm 10.75$ & $83.15 \pm 7.79$ & 13.06 & $\leq 0.001 *$ \\
\hline
\end{tabular}

*Significant $p \leq 0.05$. 
Table (6): Breast Q pre-operative and after one year in both groups.

\begin{tabular}{lllcc}
\hline Breast Q & Group A & Group B & $\begin{array}{c}\text { Test of } \\
\text { significance }\end{array}$ & $\begin{array}{c}p \text { - } \\
\text { value }\end{array}$ \\
\hline Satisfaction with Breasts (pre) & $25.05 \pm 9.79$ & $27.76 \pm 6.66$ & 0.870 & 0.391 \\
Satisfaction with Breasts (after) & $82.68 \pm 5.51$ & $77.84 \pm 6.13$ & 2.328 & $0.027 *$ \\
Psychosocial Well-Being (pre) & $22.36 \pm 8.44$ & $27.46 \pm 8.95$ & 1.635 & 0.113 \\
Psychosocial Well-Being (after) & $87.05 \pm 7.06$ & $80.00 \pm 8.76$ & 2.515 & $0.017 *$ \\
Physical Well-being (pre) & $27.63 \pm 12.26$ & $24.92 \pm 10.79$ & 0.643 & 0.525 \\
Physical Well-being (after) & $82.73 \pm 7.27$ & $81.53 \pm 10.13$ & 0.390 & 0.699 \\
Sexual Well-being (pre) & $26.00 \pm 11.47$ & $31.07 \pm 10.75$ & 1.260 & 0.217 \\
Sexual Well-being (after) & $87.05 \pm 6.44$ & $83.15 \pm 7.79$ & 1.544 & 0.133 \\
Satisfaction with Outcome & $86.63 \pm 6.99$ & $79.92 \pm 8.64$ & 2.42 & $0.022 *$ \\
Satisfaction with NAC (score 1>20) & $19.57 \pm 0.50$ & $19.07 \pm 1.75$ & 1.18 & 0.245 \\
Satisfaction with Information & $83.00 \pm 6.40$ & $83.30 \pm 6.22$ & 0.135 & 0.894 \\
Satisfaction with Surgeon & $98.31 \pm 3.35$ & $99.38 \pm 2.218$ & 1.01 & 0.322 \\
Satisfaction with Medical Team & $98.73 \pm 2.99$ & $98.15 \pm 3.50$ & 0.504 & 0.618 \\
Satisfaction with Staff & $98.26 \pm 4.12$ & $98.30 \pm 4.13$ & 0.03 & 0.976 \\
\hline
\end{tabular}

*Significant $p \leq 0.05$.

\section{DISCUSSION}

Mastopexy is the seventh most performed aesthetic surgery in the U.S. according to the most recent statistics of the American Society for Aesthetic Plastic Surgery [13]. The main goal of mastopexy is to relocate the nipple to a more centralized place on the breast mound, improve breast projection, and produce upper pole fullness. Many operative techniques, such as simple dermal reshaping, glandular redistribution, suspension to the pectoralis fascia, insertion of synthetic mesh for support, and the use of the adjacent perforator flaps, have been described [7].

Inferior glandular reshaping is a commonly used technique in mastopexy with a low complication rate. It was originally published by Ribeiro for reduction mammoplasty [14].

In the group A, a simple technique using the superomedial pedicle and lower pole dermoglandular flap was adopted to improve upper pole fullness and enhance breast projection. This was performed to compare the combination of mastopexy with either autologous tissue or an implant in terms of esthetic outcome, complications, and patient satisfaction determined using the BREASTQ score.

In the literature, different surgical techniques and outcome measures have been described regarding mastopexy with autoaugmentation or implant augmentation. Graf and Biggs introduced the use of inferiorly based flap under the pectoralis muscle loop; however, this technique disrupts normal mammary gland architecture and interferes with breast cancer screening and tethering effect of muscle contracture [15]. Ritz et al., used a pectoralis fascial strip instead of muscle to avoid interfering with breast cancer screening and pectoralis muscle contraction with reduce pain and less operative time [16]. However, there is no clear anatomical plane for dissecting the fascia from muscle, which is usually thin in the lower portion.

Many authors have reported long-term satisfactory results and low complication rateby using an inferior dermoglandular flap under the superior or superomedial pedicle [17-22]. In this study, the dermal layer of the lower pole flap was preserved to provide powerful supportive tissue, which acts as suspensory ligaments, and to provide durable fixation to the pectoral fascia, which helps to prevent the recurrence of ptosis and bottoming out by resisting the force of gravity.

The BREAST-Q is universally used for the evaluation of aesthetic and reconstructive breast surgeries $[11,23]$. To the best of our knowledge, the existing literature concerning patient satisfaction after mastopexy autoaugmentation is limited. Vindigni et al. reported an improvement in patient satisfaction after breast reshaping in patients with massive weight loss using different procedures including implant augmentation, traditional mastopexy, breast reduction, and autoaugmentation [24].

In a recent study, Grunherz et al. [12] compared mastopexy autoaugmentation using the Graf-Biggs [15] technique and implant augmentation mastopexy using a subpectoral pocket in terms of long- 
term (average 4 years follow-up) aesthetic outcomes assessed using standard breast measurements and photometric measurements, complication rate, and patient satisfaction evaluated using the BREASTQ score. In both the autoaugmentation and augmentation mastopexy groups, the most common complications were delayed wound healing $(22 \%$ and $19 \%)$, widened scars (28\% and $13 \%)$, asymmetry (17\% and $13 \%)$, and recurrent slight ptosis (11\% and 6\%), and bottoming out was observed in $13 \%$ patients in the augmentation mastopexy group. Significant decreased in SN-N distance in autoaugmentation group ( $\mathrm{SN}-\mathrm{N}$ mean difference between pre-operative and post-operative was $4.2 \pm$ $0.55 \mathrm{~cm}$ after mastopexy and $1.5 \pm 0.23 \mathrm{~cm}$ after augmentation mastopexy). Upper pole fullness and breast projection were significantly better in the augmentation mastopexy group. The autoaugmentation group showed significantly higher satisfaction with breast $(69 \pm 18$ vs. $55 \pm 16, p=0.03)$ and outcome ( $71 \pm 18$ vs. $48 \pm 26, p=0.009)$ than the augmentation mastopexy group. Additionally, in the current study, the group A showed significantly higher psychosocial wellbeing than the group B. Psychosocial wellbeing after breast surgery is an important issue in our community, and the BREAST-Q score measures the effect of breast surgery on patients' psychosocial wellbeing. Patient expresses more confident in a social setting, more self-assured and feeling less embarrassed, more attractive, and normal or like other women.

The measured values were within normal limits. However, one year postoperatively, SN-N was higher in the group B compared with that in the group A $(21.07 \pm 1.45 \mathrm{~cm}$ vs. $20.31 \pm 0.47 \mathrm{~cm})$. Moreover, N-IMF was slightly higher in the group B compared with that in the group A $(8.03 \pm 1.28 \mathrm{~cm}$ vs. $7.81 \pm 1.00 \mathrm{~cm})$. This may be because of implant weight on breast tissue, which may need additional follow-up time for the results to fully understand the effect.

The higher satisfaction in the patients who underwent mastopexy autoaugmentation could be explained by the following facts: The patients felt that their breasts were natural without a breast implant and they were not concerned about the late sequelae and risk after breast implantation. In addition, the higher prevalence of grade III breast ptosis in the group A compared with that in the group B (84.2\% vs. $46.2 \%)$ might improve patient satisfaction because the post-operative expectation is not as high as those having mild ptosis.

The most common complications were delayed healing (12\%), unfavorable scarring (12\%), seroma
(10\%), hematoma (10\%), recurrent ptosis $(10 \%)$, and fat necrosis $(5 \%)$. We observed significant improvements in satisfaction with the breast (from 23.1 to 89.2 ), physical well-being (from 39.6 to 86.3), psychosocial well-being (from 43.6 to 86.1), and sexual well-being (from 38.2 to 73.3 ); however, the BREAST-Q scores did not differ between the various reshaping techniques.

Limitation of current study includes the difficulty to get long term follow-up results in our community over many years. However, the application of the BREAST-Q allows a reliable comparison of patient satisfaction and the quality of life after mastopexy autoaugmentation and mastopexy augmentation with breast implants. Finally, authors believe that mastopexy autoaugmentation using the lower pole dermoglandular flap is a reliable, less costly, and easy to learn technique with low complication rate and high patient satisfaction, thereby decreasing incidence of bottoming out, enhancing the projection, improving upper pole shape, creating a soft and natural looking breast, and avoiding any risks and complications associated with the use of breast implants.

\section{Conclusion:}

The autoaugmentation mastopexy using the lower pole dermoglandular flap is suitable for patient requesting to improve her breast shape and volume without use of implants. BREAST-Q provides significant clinical information and evaluating the influence of the surgical procedure on the patient's regular life activities.

Acknowledgement: The authors declare that they have no conflict of interest to disclose.

\section{Funding: None.}

Conflict of interest: The authors declare no conflict of interest.

\section{REFERENCES}

1- Rubin J.P. and Khachi G.: Mastopexy after massive weight loss: dermal suspension and selective auto-augmentation. Clinics in Plastic Surgery, 35 (1): 123-129, 2008.

2- Wueringer E. and TschabitscheR M.: New aspects of the topographical anatomy of the mammary gland regarding its neurovascular supply along a regular ligamentous suspension. European journal of morphology 40 (3): 181189, 2002.

3- Regnault P.: Breast ptosis: Definition and treatment. Clin. Plast. Surg., 3: 193-203. 1976.

4- Khavanin N., Jordan S.W., Rambachan A. and Kim J.Y.: A systematic review of singlestageaugmentationmastopexy. Plasticand Reconstructive Surgery, 134 (5): 922931, 2014. 
5- Troy, Jared, Little, Andrea, Kuykendall, Lauren, Dayicioglu and Deniz: Flap-Mastopexy in Autologous Breast Reconstruction: Timing and Technique. Annals of Plastic Surgery, 80 (4): 328-332, 2018.

6- Hall-Findlay E.J.: Aesthetic Breast Surgery: Concepts and Techniques. St. Louis, MO: Quality Medical Publishing, 429-514, 2011.

7- Di Summa P.G., Oranges C.M., Watfa W., Sapino G., Keller N., Tay S.K., Chew B.K., Schaefer D.J. and Raffoul $\mathrm{W}$.: Systematic review of outcomes and complications in nonimplant-based mastopexy surgery. Journal of Plastic, Reconstructive \& Aesthetic Surgery, 72 (2): 243-272, 2019.

8- Karacaoglu and Ercan: Single Stage Augmentation Mastopexy: A Novel Technique Using Autologous Dermal Graft. Annals of Plastic Surgery, 63 (6): 600-604, 2009.

9- Ors S.: Augmentation Mastopexy with a Dermal Encapsulated Round or Anatomic Autoprosthesis. Aesthetic Plastic Surgery, 42 (1): 88-97, 2018.

10- Cano S.J., Klassen A.F., Scott A.M. and Pusic A.L.: A closer look at the BREAST-Q $\odot$. Clinics in Plastic Surgery, 40 (2): 287-296, 2013

11- Abboud L., Watfa W., di Summa P.G. and Raffoul W.: An original and simple autoaugmentation mastopexy in mild to moderate breast ptosis: Superior pedicle frontal division to achieve upper pole fullness. Gland Surgery, 6 (6): 751$752,2017$.

12- Grünherz L., Burger A., Giovanoli P. and Lindenblatt N.: Long-term results measured by BREAST-Q reveal higher patient satisfaction after "autoimplant-mastopexy" than augmentation-mastopexy. Gland Surgery, 8 (5): 516-526, 2019.

13- American Society of Plastic Surgeons (ASPS): PlasticSurgery-Statistics-Full-Report-2019. 1-25. https:// www.plasticsurgery.org/news/plastic-surgery-statistics. Accessed October 11, 2020.

14- Ribeiro L.: A new technique for reduction mammaplasty. Plastic and Reconstructive Surgery, 55 (3): 330-334, 1975.

15- Graf R. and Biggs T.M.: In search of better shape in mastopexy and reduction mammoplasty. Plastic and Reconstructive Surgery, 110 (1): 309-322, 2002.

16- Ritz M., Silfen R. and Southwick G.: Fascial suspension mastopexy. Plastic and Reconstructive Surgery, 117 (1): 86-94, 2006.

17- Botti G.: Vertical scar mammaplasty: Stable padding of the superior pole by means of a posteriorly based pedicle autoprosthesis. Aesthetic Surgery Journal, 19 (2): 116$123,1999$.

18- Colwell, Amy, Breuing and Karl: Improving Shape and Symmetry in Mastopexy With Autologous or Cadaveric Dermal Slings. Annals of Plastic Surgery, 61 (2): 138$142,2008$.

19- Kelemen N., Kannan R.Y. and Offer G.J.: A stacked technique of mastopexy: Volume redistribution mastopexy with inferior flap and superomedially based pedicle. Aesthetic Plastic Surgery, 37 (2): 349-353, 2013.

20- Hammond D.C. and O'Connor E.A.: The lower island flap transposition (LIFT) technique for control of the upper pole in circumvertical mastopexy. Plastic and Reconstructive Surgery, 134(4): 655-660, 2014.

21- Kirwan L., Wazir U. and Mokbel K.: Breast AutoAugmentation: A Versatile Method of Breast Rehabilitation; Retrospective Series of 107 Procedures. Archives of Plastic Surgery, 42 (4): 438-445, 2015.

22- Lang Stumpfle, Rubem, Piccinini, Pedro, Pereira-Lima, Lucas, Valiati and Andre: Muscle-Splitting AugmentationMastopexy: Implant Protection with an Inferior Dermoglandular Flap. Annals of Plastic Surgery, 82 (2): 137-144, 2019.

23- Pirro O., Mestak O., Vindigni V., Sukop A., Hromadkova V., Nguyenova A., Vitova L. and Bassetto F.: Comparison of Patient-reported Outcomes after Implant Versus Autologous Tissue Breast Reconstruction Using the BREASTQ. Plastic and reconstructive surgery. Global Open, 5 (1): e1217, 2017.

24- Vindigni V., Scarpa C., Tommasini A., Toffanin M.C., Masetto L., Pavan C. and Bassetto F.: Breast Reshaping Following Bariatric Surgery. Obesity Surgery, 25 (9): 1735-1740, 2015. 